\title{
Economic growth and institutions: a heterodox perspective or a new evolutionary ontology?
}

\begin{abstract}
This paper deals with the theoretical institutionalist view of economic growth According to this view, such a process should be inserted in an evolutionary environment, including new habits, routines and behavior which contrasts with the mainstream. What we intend to discuss in this paper is whether the advances brought by this view occurred due to the inclusion of heterodox features or due to a new ontology. Next we discuss the heterodox basis according to Tony Lawson and some derivative points of the critical realism as proposed by Castellacci. We will confront Lawson's view with Hodgson's contribution which shows that the advances of this approach are not due to its heterodox character, but to a new ontology derived from the evolutionary thought of Veblen.
\end{abstract}

Keywords: economic growth, institutional, economic, evolutionary economics, JEL classifications: B41, B52, And O30
Volume 2 Issue 6 - 2018

Octavio AC Conceição

Department of Economic science, Federal University of Rio Grande does Sul, Brazil

\section{Correspondence: Octavio AC Conceição, Department of Economic science, Postgraduate Program in Economics, Federal University of Rio Grande do Sul, Brazil,}

Email0000006/3@ufrgs.br

Received: September 27, 2017| Published: November 13, 2018

\section{Introduction}

Recent papers published in the Journal of Economic Issues, the Cambridge Journal of Economics, the Industrial and Corporate Change and the Journal of Institutions Economics have emphasized the direct connection between the process of economic growth and the role of institutions. Such studies do not deal with the causality relation between them which is largely ambiguous, but try to explore new conceptual nexus towards a preliminary and appreciative theorization of the nature of this relation. These subjects are some of the most complex and challenging themes in contemporary economic theory. The formalization of the process of economic growth as a predetermined path in the direction of steady state (as stated in Solow's, the New Classical and in the New Keynesian models) or its understanding as an unstable, sinuous and uncertain process (as is seen by the Institutionalists, Neo Schumpeterian and Post Keynesians) does not put an end on the analytical possibilities of this complex theme .Much has been said about the close relationship between growth and the prevailing institutional pattern in a country or region. Neo Schumpeterians such as Freeman, Perez, Freeman \& Louçã, Nelson, Dosi, Metcalfe and Institutionalists such as Hodgson, Rutherford, North, and Williamson have written about this relationship. ${ }^{1,2,3}$ This paper does not deny or question the validity of this relation. It is necessary to emphasize that such relationship is a two-way street where one survives at the expense of the other but in an unpredictable way. Many advances have happened in the area of economic growth and they have consolidated the importance of the Ancient North American Institutionalism, centered in the studies of Veblen, Commons and Mitchell. These advances contrast with part of the contemporary debate based on the theoretical core called New Institutional Economics (NIE).

This paper aims to show that the success of an institutional scenario compatible with the economic growth path has its origin in historical, social and cultural processes. This hypothesis matches the analytical reference of Ancient Institutionalism. An efficient and consistent macroeconomic policy based on the neoclassical canon is not always guarantee of an optimal path with full employment and long run equilibrium. This paper tries to show that:

a. economic growth is a process too complex to be expressed through a formalization restricted to a cast of a few variables that can be measured

b. in this process, what matters are the mutual causality relations, named circular causation by Gunnar Myrdal, where the role of the firms, the individual decisions and the institutions are fundamental

c. historical and cultural mediations are also important

d. optimality and steady state will hardly be reached in the long run due to the uncertainty and instability of the system.

These four elements suggest that the comprehension of the economic growth process is theoretically closer to the heterodox than the orthodox streams. If this assumption is right, heterodoxy must be explained, as well as its ontological nature confronting with orthodoxy and the reason why it is necessary to abandon methodological individualism. That is the reason why the economic growth process must be understood from an evolutionary perspective. This paper is divided into seven parts which discuss the following:

a. The relation between growth, institutions and the evolution process

b. The nature of heterodox thinking proposed by Tony Lawson

c. The ontology of critical realism according to Castellacci

d. Hodgson's questioning of Lawson's ideas concerning heterodoxy

e. The notion of modern evolution and Darwinian principles that lead to the auto-organization as described by Veblen

f. Hodgson's idea of a differentiated evolutionary ontology derived from Veblen

g. Finally, some considerations are made.

\section{Economic growth, institutions and evolutionism}

Many scholars emphasized the relationship between growth, institutions and evolution. Among them we can quote the neo- 
schumpeterian approach of Nelson, winter, Dosi, Freeman, Perez, Metcalfe and many others. ${ }^{1}$ In the field of institutionalism, we have two main lines: the followers of the Original Institutional Economics of Veblen, Commons and Mitchell; and, in the other side, the followers of the New Institutional Economics of Coase, North and Williamson. ${ }^{4}$

It is common in the recent analysis about this theme to assert that institutionalism has won the debate about economic development. This battle was won outside the mainstream canons. Their main assumption about the process of economic development is that it results of an efficient and unique liberal strategy, omitting the evolutionalist and institutionalist contributions. Besides, this individual behavior is neglected once the rational choice is the only parameter for their decisions. In the other side, to the institutionalists and evolutionaries the understanding of economics should follow the definition of Philip Klein, which is rooted in the heritage of the old institutionalism of Veblen and Commons. For Klein's followers, economics is a system which "embraces a body of knowledge and skills and a stock of physical equipment; it also embraces a complex network of personal relations reinforced by custom, ritual, sentiment, and dogma". ${ }^{5}$ It is important to point out that this view is not the same as the view of the World Bank which gives priority to the market institutions where organizations, firms, institutions and the economic policy restrictions act in accord with the neoclassical model. To Jameson ${ }^{5}$ one institution, the market, remains the focus of the international financial institutions such as the World Bank" despite the fact that institutionalism remains in the core of theories of development which emphasize the variability and complexity of institutional evolution. Relevant points of Veblen's institutionalism in addition to North's 'new institutionalism' have formed a pragmatic combination of constructions and approaches with epistemological and methodological advances that make it possible to advance into new issues called 'modern development institutionalism': "The challenges of the development process, and its resistance to reductionism, are the roots of modern institutionalist's contribution to understanding both development and the policies and processes that can guide development initiatives. ${ }^{5}$

In this sense, there are three approaches on economic development derived from the old institutionalism. The first comes from a lot of articles published on the Journal of Economic Issues, the second comes from the contribution of Ha-Joon Chang and the third comes from Geoffrey Hodgson's approach. The analytical perspective of the economic growth (and the economic development) cannot be understood without the inclusion of the ideas of change and structural transformation. This change has a systemic dimension so that it is impossible to think about it without considering the transformations in the microeconomic level. The interaction of micro with macro level promotes the diffusion of this process. Consequently, there is a strong correlation between the idea of change and movement with the notion of time and dynamics that makes the nexus of economic process with evolution clear. In other words, it is impossible to conceive economic growth without an evolutionary perspective. This is the reason why the Neo-Schumpeterian and the Institutionalists (specially the Ancient Institutionalists) approaches are so important. These evolutionary elements bring to the center of the debate a new interpretation of the nature of economic growth. This brings up another question: is it possible to treat the referred process in the mainstream or is it necessary to break away from it? Does this analytical object have a heterodox root? The answer is positive but, before discussing it, it is necessary to define what heterodoxy means. The nature of heterodox thinking and the advances in institutionalism will be discussed and explained in the following sections. The paper aims to explain why the advance in such an analytical perspective was due to the advances of heterodox thinking toward a new evolutionary approach. In this sense, the role of the individuals and their habits are decisive.

\section{Growth and institutionalism: a heterodox object?}

The definition of what is or not the object of heterodox theoretical analysis constitutes the reason of many discussions in the ground of political economy. Marx, in 'The Capital', distinguished the bases of the bourgeois political economy from the scientific political economy. He suggested that the difference between these two economies was the faith in the automatic mechanism of regulation by the market. Marx advocates that the difference was invented and manipulated by men, creating an antagonist, conflictive and competitive feature in the search of exceeding appropriation in the human economic activity. This affirmation contests and contrasts with the blind faith in market mechanisms (and consequent belief in the wisdom of the metaphysical dot of the invisible hand). This argument establishes the importance of the mechanisms of collective action, the importance of the patterns of behavior and the importance of the conflict rules in the management of human labor process. This emanated the institutional framework that sustained the colossal capital accumulation and technological advance alongside the $\mathrm{XX}^{\text {th }}$ century. ${ }^{6}$

This analytical perspective is convergent with the institutionalist research agenda that, in our view, has a heterodox nature. This nature is derived from the explicit critique of Thorstein Veblen to the orthodoxy, to whom the homo economicus was inert, immutable e passive. ${ }^{7,8}$ So it is important to question and to define what the main points of the heterodox nature are. What does heterodox nature consist of? Lawson ${ }^{9}$ asserted that in the last years there has been happening a great expansion in the heterodox research activities. As example he referred to the formation of the Association for Heterodox Economics (AFHE) and the conference at the Missouri University (Kansas City) in 2002 about "The History of Heterodox Economics in the 20th Century". To him, heterodoxy is a sort of umbrella which includes different research projects and traditions. All of them can be distinguished from orthodoxy by the central importance of their ontology. These modern heterodox traditions are differentiated by their specific commitments which specify substantive theories, policy measurement and analysis technique. Lawson proposes to overtake these points. He believes it is consensual that heterodox economics includes the Post-Keynesians, the Old or Ancient Institutionalists, Feminists, Marxians, Austrians and Social Economists. In general, this research agenda is characterized by the following points:

An abstract or theoretical set of recurrent themes and emphasis in a specific tradition. A multiplicity of attempts inside each tradition on theorizing about its specific and traditional themes consonantly ourselves politic posit, or to determinate the main analysis units in a specific tradition or other methodological principles based on each respective tradition. The results are frequently presented as a political theoretical position, basic analysis units or alternative methodological principles to the mainstream. An acknowledgment that it is impossible to obtain agreement inside the heterodox about theories and specific political alternatives, methodological position and the recognition that the sole common point to all heterodox tradition is the opposition to the mainstream.

By otherwise the modern project of the mainstream encloses four central theses that are criticized by heterodox. The first is that 
the respective project invariably defends and supports the current economic system, which implies the acceptance of an ideological position. ${ }^{i}$ The second is the construction of a specified theoretical model which assures optimal results. It is obtained by the assumption that the individual behavior is maximized implying to treat them as independent agents. It contrasts strongly with Veblen to whom the individual is socially embedded. Moreover, an emphatic tendency persists in this position toward mathematization, suggesting the application of their models to any place, situation and circumstances. In other words, the heterodox economy rejects the methodological reductionism because their formalistic models are inappropriate.

That is the reason why Lawson proposes that the difference between heterodox and mainstream has an ontological nature. Ontology is defined as the study (or theory) of the basic nature and the ground structure of the reality. As example, Lawson quotes Marx to whom microscopic and chemical reagents are inappropriate to analyze the economic phenomenon. Analytical methods are appropriate to a certain type of matter and others are not. The same principle is valid to mathematical methods that are inadequate to social situations. The third theses is that the ontological supposition, implicit in the modern research project of the mainstream, points out to an opposite vision related to heterodox contribution. The formalistic method of the first requires the existence of closed systems, through which eventual regularities can happen (deterministic or stochastic). Mainstream adopts a deductive version which proposes fundamental relations restricted to the limits of causal sequence. ${ }^{9}$

If the social reality depends on the human activity-which is in a permanent process of transformation-so this process can be understood as intrinsically dynamic or processual. An example is language, which is a condition to the human communication as the speech action. The cumulative addition of these actions continuously reproduces and modifies the language system. Thus this system is intrinsically dynamic because their nature is continuously transformed by a process. It is true to all forms of social reality. The alternative ontology sketched above systematizes the preconceptions of many heterodox traditions and explains their persistent opposition to mainstream. The postKeynesian emphasis on the uncertainty is inserted in this supposition. The same can be said about the institutionalist emphasis on the evolutionary method and in the technology as a dynamic strength. Both of them sustain that the social system must be seen as a process. What drives the heterodox opposition to mathematic formalism is a singular world view related with the formalistic models proposes. Therefore, the various heterodox traditions may be identified by their orientation or practices concerning the social ontology described. The set of projects systematized as heterodox are in first instance oriented by a methodological manner and systematized through the critical realism in economics.

Thus the distinction among the various heterodox projects, as well as the emphasis on their basic orientation, is more a result of an internal debate and disagreement on substantive theories and political posits than an appropriated basic analysis units and other methodological principles. Post-Keynesians and Institutionalists may

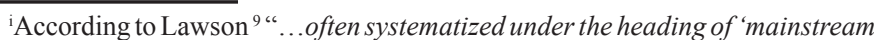
economics as ideology'. To state the moral: the entire enterprise of neoclassical economics is rigged to show that laissez-faire produces optimal outcomes, but for the disruptive operation of the odd externality (a belated correction) here and there. (...) How is this rigging said to be achieved? One component of the most common strategy is everywhere to stipulate that human beings are rational (meaning optimizing) atomistic individuals." be seen as coherent between them. And such a coherency is given by the form how their interpretations are effectively compromising with the described ontology. Lawson's fourth thesis is that if ontology can explain the differences between the heterodox and the modern mainstream (where the ontological compromises identify PostKeynesian, Institutionalists, Feminists and others), what distinguishes one heterodox tradition from the other are their particular orientations, their relations and emphasis, and not their answers or principles. This social ontology provides a conception of the properties of all the social phenomena, which are opened, structured, intrinsically dynamic in the sense that are dependent of the social transformation and are internally concerning social relations. There is no reason to suppose that the existence of another economic sphere in the social realm destitute of these properties may be possible. The materials and principles of the social reality are the same among economics, sociology, politics, anthropology, human geography and all the others disciplines concerning the study of social life. Thus Lawson proposes that the distinction between heterodox and mainstream economics must consider the following points:

a. This opposition is not derived from substantive outcomes or basic analysis units but according to the methodological orientation. The modern project of the mainstream insists that the economic phenomena should be investigated through mathematical deductive forms.

b. Intellectual fails and limitations of the mainstream project are in the emphasis on mathematic deductive reasons. They are inappropriately facing to the social nature. In other words, the method of the mainstream's ontological propositions does not match with the nature of social reality.

c. The heterodox opposition is based on the form of apprehending the situation expresses in the previous item.

d. The modern heterodoxy has an ontological orientation. It is distinguished from the mainstream by the disposition to deal with theory and method compatible with the nature of social reality.

e. The individual heterodox tradition distinguishes itself by each particular substantive orientation, interests and emphasis and not by their allegations or theoretical outcomes, methodological principles or political posits.

Thus the heterodox ontology of Lawson accepts multiple unfoldings but it does not provide specific elements to build a theorization about economic growth, institutions and evolution. Such a task must be made by each specific heterodox approach. In this sense, we will discuss Castellacci's proposition of an ontological evolutionary theorization departing from Lawson and relating to economic growth and institutions.

\section{Critical realism: an ontology derived from Lawson}

Castellacci ${ }^{10}$ following Lawson's same logical thought of proposing to join the evolutionary theorization of economic growth with the critical realism, of which Lawson is one of the main exponents. This interpretation has specific and fundamental features because evolutionary ontology is complex, differentiated, structured, systemic, opened, ever changing and submitted to radical uncertainty. Methodologically, such ontology is increasingly based on appreciative theorization and in the interdisciplinary character. Thus critical realism can be an important philosophical and methodological fundament to 
the development of future evolutionary theory on economic growth. The same can be said about the institutionalist theorization. Since the reality is so complex, it is impossible to reduce it to a unique interpretation. So the reality interpretation should be composed by three interrelated levels:

a. the real (deep) level of structures and generative mechanisms

b. the actual level of events and states of affairs

c. the empirical level of observed phenomena, perceptions and impressions. ${ }^{10}$

Critical realism ${ }^{\mathrm{ii}}$ in economics points out to the main limitations of neoclassical economics and tries to build a philosophical and methodological fundamental to a large set of alternative approaches That is the case of the Neomarxists, the Post-Keynesians and recently the Evolutionaries. To Lawson ${ }^{11}$ there are a strong connection between the evolutionary theory of economic change (departing from the seminal work of Nelson \& Winter) and the critical realism philosophy. ${ }^{\text {iii }}$ Castellacci proposes a critical realism interpretation of the evolutionary theory of economic change by answering if it can constitute a philosophical and methodological fundament to the evolutionary theorization of economic growth. The novelty is that this author proposes a broader definition of this process concerning the original of Nelson \& Winter. Castellacci includes three other dimensions in the evolutionary theorization of economic growth that was not sufficiently systematized by Nelson \& Winter Such dimensions are the Schumpeterian long wave's theory, the technological gap in the study of catching up and falling behind and the innovation system structure. It constitutes a fertile realm to the advance of an evolutionary theorization of economic growth. To Castellacci ${ }^{10}$ these considerations are sufficient to the formulation of an 'evolutionary ontology' compatible with critical realism. However, this point is not acceptable because an evolutionary ontology should include arguments linking institutional and technological environment with habits, behaviors and the idiosyncrasies of the individuals. Due to this, Hodgson's argument will be discussed, once he drives his focus to an evolutionary ontology centered in Veblen and to the concept of 'reconstitutive downward causation'. This notion is fundamental by including individual habit in the institutional environment.

\section{The Lawson $\mathbf{x}$ hodgson controversy and the heterodox limits}

Lawson's argument is meritorious and is an important analytical effort towards a heterodox ontology. But it does not stress all the institutionalist analytical potentiality mainly when dealing with Veblen's thoughts. That is the reason why we will discuss Hodgson's reply to Tony Lawson, who seeks to identify some elements of a differentiated evolutionary Veblenian ontology. Ontologically Hodgson emphasizes that the Darwinian evolutionism is close to Veblen institutionalism and the opposition between mainstream and heterodoxy cannot be seen in the terms of the Lawson proposition. This author believes that the different heterodox approaches are distinguished not by their ontological propositions but by different

${ }^{i i}$ To Castellacci ${ }^{10}$ the main references of critical realism are Lawson ${ }^{12,13} \mathrm{We}$ cannot neglect the seminal contribution of Roy Bhaskar.

iii Despite it Castellacci ${ }^{10}$ emphasizes that: "these previous works also point to possible problems in interpreting evolutionary growth theorizing from a critical realist perspective, articularly in relation to the coexistence of realist and positivist features in Nelson and Winter's distinction between 'formal' and 'appreciative' theorizing'. questions of interest. Hodgson disagrees because such a distinction (a) is unconvincing and (b) Lawson's heterodox community ignores, inside this stream, a specific institutional field and the evolutionary economics of Veblen, which focus algorithms and rules of the system. ${ }^{12}$

Lawson $^{13}$ also discusses the essential features of the old institutionalism, which emerged in 1890 and became very strong in USA in the first half of $\mathrm{XX}^{\text {th }}$ century, involving many economists and inspiring many books and papers. In Hodgson's view Lawson focuses the referred approach in a very restricted form, omitting its nature and core. Besides, he omits any discussion about the evolutionary nature of the old institutionalism that is deepened in Hodgson ${ }^{14}$ For example; the formation of endogenous preferences is a characteristic definition of the old institutionalism. However, it is refused by Lawson because Friedrich Hayek also recognizes that intentions and preferences may be molded by institutional circumstances. Hodgson agrees with both of them and with many other economists, including Marxists and Keynesians, because all of them acknowledge the possibility of endogenous preferences. Moreover, Alfred Marshall also accepted that individual wills and preferences could be molded by circumstances. ${ }^{\text {iv }} 15$ The point that Hodgson emphasizes is that these observations do not weaken the arguments of his paper written in $2000,{ }^{16}$ where he never tried to schematize "all" the features of the old institutionalism. What he adopted was a necessary, but insufficient criterion to describe the old institutionalism.

The question if heterodox economics (including the old institutionalism) can be differentiated, in terms of ontology, from the mainstream, as argued by Lawson, is also contested by Hodgson. It is contested because the argument that the distinctions inside the heterodox traditions are not primarily ontological is false, but concerning different interest questions. Lawson affirms that what unifies heterodoxy is the rejection of the mathematical deductive methods adopted by the mainstream, which supposes that the world is closed. To Hodgson all theorization involves some type of abstraction which implies some partial or temporary limitation of the theory. The heterodox economics is no exception. Consequently, Lawson's attempt of distinguishing mainstream from heterodoxy fails. Is the criterion of "deductivism" adequate to distinguish old institutionalism from mainstream approaches? Lawson states that the old institutionalists from Veblen to Galbraith were very cautious concerning the use of deductive and ahistorical methods. The rejection of a theorization dominantly aprioristic has been a persistent feature of the old institutionalists writings views deductivism presumably as "occasional regularities" or "constant conjunctions of events" or "state of affairs", with regularities such as "whenever there is $\mathrm{x}$ event then there is $\mathrm{y}$ event." Philosophically, this is an atypical definition of deductivism because it refers to empirical activities in relation to events, rather than logical deductions from proposals. The consequence of this atypical definition is that the most prominent methods based on empirism, including the econometrics, are also deductivists that bought this definition, supposing that they are also eventual regularities. Lawson's extensive critic to econometrics confirms this instance. Generically,

${ }^{\text {ivHodgson }}{ }^{15}$ emphasizes that: "However, a key difference with the old institutionalists is that) - contrary to Marx, Marshall, Keynes and Veblen — did not regard it as the task of 'economics... or any other social science' to explain individual preferences or behavior. Hayek accepts endogenous preferences but does not see their explanation as within the scope of economics. I quoted Hayek on this in Hodgson ${ }^{16}$ and contrasted it to the old institutionalist belief that the explanation of individual dispositions, purposes or preferences was partly within the scope of economics." 
he sustains that econometrics methods are inappropriate unless closed systems exist or are near the reality. Many prominent post-Keynesian economists however defend econometric methods and many Marxists incorporate mathematical methods. The Sraffian have in a long time heterodox credentials. To Lawson mathematical methods and models are not intrinsically inadequate but its use depends on the form on how the closure or the proximity to the reality is obtained. However, this degree of proximity is never specified so that it is difficult to use his criterions to distinguish mainstream from heterodoxy. Until he redefines this logic it is necessary to associate mathematic economics to mainstream, despite the fact that many heterodox traditions use this method, including formal theorizing in Marxian, Sraffian and PostKeynesian traditions.

The answer to the question if can mainstream be distinguished from old institutional economics in ontological terms induced Lawson to the same problems. To him this approach distinguishes from the mainstream in the form by which he describes both of them. In other terms, the differences between them are resulting from the fact that the old institutionalism varies in terms of its philosophic and theoretical core hypothesis. However, inside this variety there were elements closer to what Lawson specified as mainstream than heterodox. ${ }^{v}$ Hodgson $^{4}$ emphasizes that the positivist spirit was introduced in the institutionalism during the interwar period, despite the previous advisers about the limits both of this thought as well as the empiricism. The consequences of this change in the fundamental philosophical perspective of the old institutionalism toward positivism implied the acceptance of eventual regularities defined by Lawson as deductivism, which is also seen by him as a feature of the mainstream. As a result, Lawson's criteria does not identify a clear division between mainstream and the old institutionalism. It is interesting to observe that since the growing of the experimental economics until it prominence in the 90s the own mainstream became less aprioristic and more inductivist based on evidence..$^{17}$ Ironically, the methodological approaches inside the modern mainstream had become nearer of the positivist variety of the institutionalism that was predominant in the $20^{\text {th }}$ and $30^{\text {th }}$ years. Given that the Lawson's definition of deductivism includes empiricists and aprioristic, his definition is also insensitive with this important and prominent change in the mainstream, as well as the growing affinities with positivistic tradition inside the old institutionalism. Thus it is necessary to explain what the new institutionalist contribution on the theme consists of, with the purpose of overcoming some points not elucidated by Lawson. The emphasis given in the beginning of this paper on the ontological character of the economic growth process and institutions claim an exploitation of the fundamental elements of this proposition. That is the reason why the main points of the ontological approach derived from Veblen will be explained in the sequence

\section{The notion of evolution, Darwinism and self- organization}

The debate on economic growth and institutions emphasizes that this process cannot be learned without an evolutionary environment. The comprehension and systematization of the referred process without this referred approach is extremely poor, fragile and empty from the institutionalist and methodological points of view. Institutions, economic growth and evolutionism are inseparable.

"Many institutionalists, exceptuating Veblen, had been favorable to inductive methods such as Wesley Mitchell, Morris Copeland and John Maurice Clark.
Hence, it is necessary to discuss the meaning of the idea of evolution. Institutionalists linked to Veblen's tradition for instance Geoffrey Hodgson ${ }^{17}$ gave a systematic treatment to the concept of evolution bringing it near to institutional environment. Hodgson ${ }^{18}$ answer 'what is evolution?"“(...) [a]t least etymological or historical grounds, there is little point in trying to give the word a narrow or well-defined meaning. Etymologically, like the word 'development', 'evolution' derives from the Latin verb "volvere". (...) The word 'evolution' therefore derives from the Latin word associated with a specifically directional and predestined activity; the scroll is unrolled to reveal that which is already written within."

Spencer did much more than Darwin to popularize the term evolution. In the first edition of "The origin of Species", Darwin did not use this expression and just one time wrote evolved. Nowadays evolution is used in many senses so that it is impossible to elect a unique and exclusive Darwinian definition. Instead of an unfruitful discussion about the meaning of the word evolution, Hodgson ${ }^{18}$ prefer to analyze the phenomena mentioned: "We refer to a broad class of systems and populations of entities, including all feasible manifestations of development and change. We then show, under some minimal conditions, that ongoing change in such systems is inevitably Darwinian in the sense that it must involve Darwin's central principles of variation, inheritance and selection. ${ }^{19}$ Over the last 300 years, the evolutionary thought has advanced tremendously, originating new insights with highly complex outcomes. However, the main exponents of this thinking, such as Bernard Mandeville, David Hume, Adam Smith and Carl Menger pointed out that social order and institutions result from individual interactions. Following Hodgson ${ }^{19}$ it is important to emphasize that: Rather than simple, mechanical systems, the objects of our discussion are complex systems, at least in the sense that they involve a variety of entities that interact with one another. Such complex systems produce some outcomes that are not willed by any individual entity and have properties that do not correspond to any individual entity taken alone."

Such complex systems include a population of entities with specific types, whose members are similar in general, but inside each group there is variation due to genesis or circumstances. Since all the entities are mortal and degradable they need to consume material and energy to survive or to minimize degradation. But once they cannot access all the environmental resources all the time they face an omnipresent problem of local and immediate scarcity. These entities are permanently involved in a struggle for existence which Darwin refers to (1859). This term constitutes the basis of the Darwinian principle of heritage that refers to the wide class of mechanisms, including replication and descends, by which information related to the adaptation are retained, preserved, passed on or copied through time. Hodgson ${ }^{19}$ state that: "Examples of populations in such systems are plentiful both in nature and in human society. They include every biological species, from amoebas to humans. They would include self-replicating automata, of the type discussed by von Neumann. ${ }^{20}$ In addition, and important for the social scientist, they include human institutions, as long as institutions may be regarded as cohesive entities having some capacity for the retention and replication of problem solutions. Such institutions would include business firms."

This wide scheme of the evolutionary system is crucial to understand that evolution must include three Darwinian principles: 
variation, inheritance and selection ${ }^{v i}$. Individually, firstly, it is necessary to emphasize that there must be some explanation of how variety occurs and how it is replenished in a population. In biological systems this sort of answer involves genetic recombination and also rare mutations. There are no analogous mechanisms in the evolution of social institutions, but existence and feedback of variety remain a vital issue in evolutionary research. ${ }^{21}$ Second, there must be an explanation about the form useful information regarding solutions to particular adaptive problems is retained and passed on. In biology, these mechanisms often involve genes and DNA. In social evolution, includes the replication of habits, customs, rules and routines. To Hodgson ${ }^{18}$ "there must be some mechanism that ensures that such solutions (embodied in habits, routines or whatever) endure and replicate; otherwise, the continuing retention of useful knowledge would not be possible".

Third, there must be an explanation about the fact that the entities have different longevity and fecundity, so that in a given context some of them are more adapted, some survive more than others, and some are more effective than others concerning the generation of descendants. From this, emanates the selection principle which involves a set of previous entities, each one interacting with its own environment, and being transformed into another set, where all the members of these new set are sufficiently similar to the members of the previous environment and where the resulting frequencies of the entities depend on their properties in the environment context. Through selecting a set of entities, a population, gradually adapts itself as an answer to the criteria's defined by the environment factor.

It is necessary to emphasize that the outcomes of the selection process are neither moral, nor just, and there is no commitment of being necessarily optimal or the best concerning their precursors. So far efficiency is relative to the given environment, and it is tolerable rather than optimal. Consequently, state what follows:"Darwinism does not assume that selection brings about globally efficient or (near) optimal outcomes, and in certain instances selection can even lead to systematic errors. There is no reason to believe that the special requirements needed to asymptote global efficiency are commonly present in nature or society."

Another important question is about self-organization. This process shows that it is possible to obtain self-organized and complex outcomes without the presence of a designer or a planner to conduce the movement toward a previous way. This assert contrasts with a common view inside the social science which "(...) all social phenomena are the result of conscious design, many complex and efficacious human institutions such as language and common law are not the outcome of an overall plan" (idem, p. 6).Self-organization is so important in nature that it is easy to observe that complex and intricate patterns and outcomes can be obtained through interactions and accumulated steps. In the words of Hodgson 22 "Just as self-organization reminds us that not every human creation is the result of a plan, it also removes the hand of God from explanations of many wonders of nature. But is selforganization sufficient to explain the origin of species and all complex biological phenomena? The definite answer is no. Darwin's principle of selection is also required. Unfortunately, some writers, marveling at the outcomes of self-organization, have proposed that it is sufficient as an evolutionary explanation of all complex phenomena."

viTo Hodgson" "These are the broad Darwinian theoretical requirements. They do not themselves provide all the necessary details, but nevertheless they must be honored. Otherwise the explanation of evolution will be inadequate."
Despite the great importance of self-organization, not all human creation is a result of a plan, so that self-organization is insufficient to explain the origin of the species and the complex biological phenomenon. ${ }^{\text {vii }}$ It is a necessary but not a sufficient condition. It is also necessary to include the Darwinian principle of selection. Both of them constitute the nature of Darwinian process. The absence of one or other will obstruct this process. Some writers charmed with the outcomes of self-organization, have proposed that it is sufficient as an evolutionary explanation of all complex phenomenon. In Biology as in any other social sciences, these writers have not emphasized the importance of evolutionary selection and the Darwinian intellectual revolution. In biology, neither the individuals nor the species and the ecosystems are completely self-transformers. Evolution happens inside the opened systems including endogenous and exogenous changes. Commonly the evolution occurs through internal changes and interaction with the environment. ${ }^{23}$ the isolation mechanisms have important effects on the evolutionary trajectory of the ecosystems, because isolation asserts new variation to the time to evolve slowly, despite the fact that it reduces the variation level that is being produced. The breakdown of the isolation mechanisms increases the variation level presented by the population taking them some time to surpass the system rigidity. In biology, many of the changes in a specific area are due to the introduction of existing species from other region which interacts with their neighbors affecting the evolution course. Exogenous chocks, as the meteors impact and climatic changes, are source of influence on evolutionary process taking to the expansion of some species and the extinction of others. In the same way, sometimes changes stimulated exogenously in the social evolution have a great importance because cultural mechanisms of imitation and conformism tend to reduce internal varieties and can take to institutional ossification. Some examples in this sense quoted by North $D^{24}$ are the century XVII revolution in England, the Meiiji restoration in 1868, and the Japan and German occupation by Americans in $1945 .{ }^{25}$ The course of institutional evolution was altered by the intrusion of new forces across the boundaries of the system, as in many other cases of institutional transformation being promoted by invasion or other forces from outside". This argument emphasizes the importance of the Darwinian contribution to the development process involving habits, customs, technologies, institutions and all the economy.

That is the reason why the notion of 'reconstitutive downward causation' proposed by Hodgson ${ }^{14}$ is essential to the definition of habits, which will constitute the institutional framework. ${ }^{\text {viii }}$ In a

${ }^{\text {vii Following Hodgson }}{ }^{22}$ In both biology and the social sciences, they have thus downplayed the importance of evolutionary selection and the importance of the Darwinian intellectual revolution. Although he embraced much of belittled its significance with the statement: 'Those eighteenth-century moral philosophers and the historical schools of law and language might well be described.

as Darwinians before Darwin. . . . A nineteenth-century social theorist who needed Darwin to teach him the idea of evolution was not worth his salt'. This underestimates the importance of the specific contribution of Darwin, especially in terms of the principle of selection, and encourages others to place more emphasis on the emergence of undesigned social order than on the sifting and selection of rival social institutions."

viiiTo Hodgson ${ }^{23}$ "Institution are enduring systems of socially ingrained rules. They channel and constrain behavior so that individuals form new habits as a result. People do not develop new preferences, wants or purposes simply because "values" or "social forces" control them. Instead, the framing, shifting and constraining capacities of social institutions give rise to new perception and dispositions within individuals. Upon new habits of thought and behavior, new preferences and intentions emerge. As a result, shared habits are the constitutive material of institutions, 
close position, Douglass North, who recognizes the importance of the mental models that perform the economic structure and the institutions? This point suggests a convergence between the new and the old institutionalism, rehabilitating both the concept of endogenous preference and the individual rationality created culturally and institutionally. This convergence will be treated specifically in the next section suggesting a Veblenian evolutionary ontology. That is the answer why this ontology should be funded in heterodox and evolutionary propositions.

\section{Beyond the heterodoxy: evolutionary veblenian ontology}

Institutionalism - including Thorstein Veblen, John R. Commons, Wesley Mitchell, Morris Copeland e Clarence Ayres-has a great variety of approaches that induced different tendencies in terms of philosophical and psychological propositions. For example, Veblen incorporated the psychology of instincts and habits and rejected positivism while Ayres followed a reverse instance. It contrasts with the common and unsustainable view that Ayres was a follower of Veblen tradition. The ascension of positivism, the decline of the instincts and habits psychology, and the behaviorism ascension in the period of 1900-1930 led institutionalism to a crises concerning its identity and fundamental presupposition. These crises prevented Commons and others of formulating an adequate philosophical fundament to institutionalism. Such deficiencies are the answer for the subsequent decline of this thought.

However, Veblen's position retrospectively is seen by Hodgson ${ }^{23}$ as strictly modern compared to the recent advances in philosophy, psychology, sociology, anthropology and economy. Veblen was influenced by pragmatist philosophy, which after being eclipsed during all the $20^{\text {th }}$ century reemerged becoming, nowadays, one of the most influent philosopher structures in the intellectual scenario. ${ }^{26}$ After the hegemony of behaviourism in psychology from the 20's to the 60's, the evolutionary approaches inspired in William James and others were resurrected. Also, the Veblenian concept of habits defined in terms of acquired dispositions reemerged in the modern psychology, becoming explicit that Veblen's position is much more viable today while improvements and advances were made in the sense of replacing Kantian philosophy of Veblen by an adequate form of realism.

Hodgson ${ }^{23}$ advances in the sense of proposing the fundamental propositions of Veblen's institutionalism, identifying six basic negative propositions, in the critical sense -including rejection to positivism, methodological individualism and collectivism methodological-added to thirteen basic positive propositions - including the principle of universal causation, the principle of evolutionary explanation, and the idea of reconstitutive downward causation. ${ }^{\text {ix }}$ However, these nineteen

providing them with enhanced durability, power and normative authority. (...) The mechanism through which culturally and institutionally specific rules of cognition and action become imprinted in the human mind is through the formation of habits. All reason, deliberation and calculation depend upon the prior formation of habits. Habits are formed through repeated thoughts or behaviors in a specific type of social setting. Habits are individual neural connections and mechanisms, but they bear a social imprint. Reconstitutive downward causation, from specific social structure to individual, operates by creating and molding habits."

ix In the last years, specifically since 2012, Hodgson substituted this term by "reconstitutive downward effects", considering that the term effects are more adequate than causation. propositions are insufficient to complete all Veblenian institutionalism. It is necessary to include additional key elements that, despite necessary, “(...) were unclear, underdeveloped or absent in Veblen's work' I add an additional eight propositions (including a layered ontology and an explicit focus on emergent properties) that are 'vital for a Veblenian theoretical system rebuilt on emergentist foundations. To Hodgson twenty-seven propositions schematize partially the philosophical fundaments of the Veblenian institutionalism. The great part of these propositions is ontological and concerned with the nature of social being, causality, evolution, Darwinian population thought and much more. The Veblenian institutionalism both in its original form as in the resuscitated form can claim a particular ontology, which contrasts with many other approaches coming from the heterodox and the mainstream. For example, the Veblenian notion of the instinctive intelligence contrasts with the dominant view of the social scientists, both heterodox and orthodox, because they saw instincts and intelligence as opposing themselves. Besides, Veblen's insistence that the assumptions concerning human capabilities should be consistent with the evolutionary explanations (in Darwinian terms) was absence in the great majority of the mainstream and heterodox thought. However, Veblen did not develop and resolve an adequate social ontology. It is important to point out that his Darwinian and evolutionary general instance indicated a potentially fertile ontology which will be realized on the future theoretical works. Partly, the resuscitated Veblenian approach concerns algorithmic and incremental nature of the decision making. The orientation of the referred approach is given toward the comprehension of the processes, instead of the equilibrium, as emphasized by Lawson ${ }^{13}$ such the social reality as the individual's capabilities are conceived in terms of the various systems of processual rules. In Veblen this system of rules was replaced by a Darwinian generalized structure where the principles of variation, retention and selection were used to explain their evolution. In this context Hodgson proposes that these elements are convergent with a possible change in the social sciences similar to a "gestalt", but in an opposite sense of the approaches linked with notions of incremental change and equilibrium of the mainstream. In Hodgson's words:"These and similar elements elsewhere coincide with a possible gestalt shift in the social sciences, away from conceptions of incremental change and equilibria, where everything potentially impinges on everything else, to a notion of limited interconnectedness within social systems essentially composed of structures and algorithmic processes of rules."

Due to this new gestalt and particularly to the recent development of the new and the old institutionalism, what will emerge in the future as 'institutional economics' will be very different of what was dominant in the $80^{\text {ss }}$ and 90 's in this realm. Consequently, the trial of delimitating sharply what distinguishes mainstream from heterodox may be useless and unconvincing. In other words, by distinguishing them in ontological presuppositions it will be neglecting the fact that all theorization involves some type of enclosure, an unacceptable distinction in Lawson's terms. Besides, the distinction among the different heterodox approaches departing, not from their respective ontological presuppositions, but from their various interest questions omits the great diversity of fundamental hypothesis of the heterodox economics and the old institutionalism. It also omits the specific ontological focus on algorithms and rules of the system featured as the modern evolutionary or institutionalism version. And this modern approach has a strong Veblenian root. 


\section{Conclusion}

The complex relation between economic growth and institutions involves much more than a causal relation. It includes a new analytical approach that should show the interconnections among complex variables in an opened system, which transcends the bounds of the conventional analysis. That is the reason why we think that the elements referred are present in the heterodox realm. Castellacci following Lawson's propositions associates the evolutionary theorization of economic growth with critical realism. To him this association contains the elements of a new ontology. We do not disagree with this proposition. However, we think that fundamental elements, as the ones proposed by Hodgson, are omitted in the referred view. In other terms, Castellacci's ontology should necessarily include an analysis of the individuals, their habits, rules, norms and behaviors. These elements are essential to constitute a new and heterodox ontology of the economic growth process. Hence, we think that Hodgson's arguments regarding these points generate a new ontology originated from the evolutionary and Darwinian contribution of Veblen. This new ontology, called by Hodgson as a new gestalt in social sciences, is an important novelty in the research agenda about economic growth.

\section{Acknowledgements}

None.

\section{Conflict of interest}

The author declares there is no conflict of interest.

\section{References}

1. Nelson RR, Winter SG. An Evolutionary Theory of Economic Change. Cambridge, Massachusetts: Harvard University Press; 1982. 454 p.

2. Hodgson Geoffrey M. The Revival of Veblenian Institutional Economics Journal of Economic Issues. 2007;14(2):325-340.

3. Rutherford MH. The Old and the New Institutionalism: Can Bridges be Built? Journal of Economic Issues. 1995;29(2):443-451.

4. Hodgson Geoffrey M. The Evolution of Institutional Economics: Agency, Structure and Darwinism in American Institutionalism. London and New York: Routledge; 2004a. 534 p.

5. Jameson Kenneth P. Has Institutionalism Won the Development Debate? Journal of Economic Issues. 2006;40(2):369-375.

6. Hodgson Geoffrey M. Characterizing Institutional and Heterodox Economics-A Reply to Tony Lawson. Evolutionary and Institutional Economics Review. 2006;2(2):213-223.

7. Hodgson Geoffrey M. Economics and Institutions: A Manifesto for a Modern Institutional Economics. Philadelphia: Polity Press and University of Pennsylvania Press; 1988. 264 p.
8. Veblen Thorstein B. Why Is Economics Not an Evolutionary Science? Quarterly Journal of Economics. 1898;12(3):373-397.

9. Lawson T. The nature of heterodox economics. Cambridge Journal of Economics. 2006;30(4):483-505.

10. Castellacci Fulvio. A critical realist interpretation of evolutionary growth theorizing. Cambridge Journal of Economics. 2006;30(6):861-880.

11. Lawson T. Reorienting Economics. New York: Routledge; 2003. 21 p.

12. Lawson T. Economics and Reality. New York: Routledge; 1997. 128 p.

13. Lawson T. The Nature of Institutional Economics. Evolutionary and Institutional Economics Review. 2005;2(1):7-20.

14. Hodgson Geoffrey M, Knudsen T. The Complex Evolution of a Simple Traffic Convention: The Functions and Implications of Habit. Journal of Economic Behavior and Organization. 2004;54(1):19-47.

15. Hodgson, Geoffrey M. What Is the Essence of Institutional Economics? Journal of Economic Issues. 2000;34(2):317-329.

16. Hodgson Geoffrey M. Veblen and Darwinism. International Review of Sociology/Revue Internationale de Sociologie. 2000;14(3):343-361.

17. Hodgson Geoffrey M. Economics in the Shadows of Darwin and Marx. Essays on Institutional and Evolutionary Themes. Cheltenham: Edward Elgar; 2006. 265 p.

18. Hodgson Geoffrey M. What Are Institutions? Journal of Economic Issues. 2006;40(1):1-25

19. Hodgson, Geoffrey M, Knudsen T. Why we need a generalized Darwinism, and why generalized Darwinism is not enough. Journal of Economic Behavior \& Organization. 2006;61:1-19.

20. North DC. Institutions. Journal of Economic Perspectives. 1991;5(1):97112 .

21. Nelson RR. Recent Evolutionary Theorizing About Economic Change. Journal of Economic Literature. 1995;33(1):48-90.

22. Hodgson Geoffrey M. Economics and Evolution: Bringing Life Back Into Economics. Ann Arbor: Polity Press and University of Michigan Press MI; 1993. $381 \mathrm{p}$.

23. Hodgson Geoffrey M. The Ubiquity of Habits and Rules. Cambridge Journal of Economics. 1997;21(6):663-684.

24. North DC. Economic Performance through Time. American Economic Review. 1994;84(3):359-368.

25. North Douglass C. Understanding The Process of Economic Change. Princeton: Princeton University Press; 2005. 200 p

26. Pagano U. Bounded Rationality, Institutionalism and the Diversity of Economic Institutions. In: Louçã F, Perlman M, editors. Is Economics An Evolutionary Science? The Legacy of Thorstein Veblen. UK: Edward Elgar publishers; 2000. $256 \mathrm{p}$. 